\title{
Depicting the tree of life in museums: guiding principles from psychological research
}

\author{
Laura R Novick ${ }^{1 *}$, Jane Pickering ${ }^{2}$, Teresa MacDonald ${ }^{3}$, Judy Diamond ${ }^{4}$, Shaaron Ainsworth ${ }^{5 \dagger}$, Adriana E Aquino ${ }^{6 \dagger}$,
} Kefyn M Catley ${ }^{7 \dagger}$, Jeff Dodick ${ }^{8+}$, Evelyn Margaret Evans ${ }^{9 \dagger}$, Camillia Matuk ${ }^{10 \dagger}$, Janis Sacco ${ }^{2 \dagger}$ and Monique Scott ${ }^{6 \dagger}$

\begin{abstract}
The Tree of Life is revolutionizing our understanding of life on Earth, and, accordingly, evolutionary trees are increasingly important parts of exhibits on biodiversity and evolution. The authors argue that in using these trees to effectively communicate evolutionary principles, museums need to take into account research results from cognitive, developmental, and educational psychology while maintaining a focus on visitor engagement and enjoyment. Six guiding principles for depicting evolutionary trees in museum exhibits distilled from this research literature were used to evaluate five current or recent museum trees. One of the trees was then redesigned in light of the research while preserving the exhibit's original learning goals. By attending both to traditional factors that influence museum exhibit design and to psychological research on how people understand diagrams in general and Tree of Life graphics in particular, museums can play a key role in fostering 21 st century scientific literacy.
\end{abstract}

Keywords: Tree of Life; Informal science education; Evolution education; Diagram design

The affinities of all the beings of the same class have sometimes been represented by a great tree. I believe this simile largely speaks the truth. The green and budding twigs may represent existing species; and those produced during each former year may represent the long succession of extinct species... As buds give rise by growth to fresh buds, and these, if vigorous, branch out and overtop on all sides many a feebler branch, so by generation I believe it has been with the great Tree of Life, which fills with its dead and broken branches the crust of the earth, and covers the surface with its ever branching and beautiful ramifications.

\section{(Darwin 1859, pp. 129-130)}

The Tree of Life has been an enduring image in many cultures' folklore for thousands of years. In his 1859 publication, On the Origin of Species by Means of Natural Selection, Charles Darwin used this Tree to represent the

\footnotetext{
* Correspondence: Laura.Novick@vanderbilt.edu

${ }^{\dagger}$ Equal contributors

'Department of Psychology \& Human Development, Vanderbilt University, 230 Appleton Place, Peabody College \#552, Nashville, TN 37203-5721, USA Full list of author information is available at the end of the article
}

idea of shared ancestry among the species of past and present life on Earth. Darwin's Tree of Life is a fundamental scientific construct that (a) depicts evolutionary relationships among Earth's biodiversity and (b) is the focus of a large research effort to reconstruct the evolutionary origins of all taxa (e.g., see http://tolweb.org/tree/, Cracraft and Donoghue 2004). This mega-science effort, much of which is occurring in museums, is revolutionizing our understanding of the place of humans in nature and providing knowledge that is critical to a variety of 21 st century challenges ranging from medicine to agriculture to the preservation of Earth's environment (e.g., National Research Council 2009a). Research and evaluation studies of Tree of Life exhibits have found that museum visitors show great interest in understanding these relationships (Block et al. 2012; Diamond and Evans 2007; Giusti 2008; Reinfield 2010).

A recent survey suggests that public educational use of trees may be increasing: Approximately one third of informal science institutions surveyed already use evolutionary tree graphics in their exhibitions (MacDonald and Wiley 2012), and zoos and botanic gardens, which have not traditionally included evolutionary diagrams in their displays, are increasingly doing so (MacDonald and 
Wiley 2012; Weiss 2006). Given the importance of these graphic elements in museum exhibits and the role that museums play in communicating about evolution to the public (Diamond and Evans 2007), it is timely to explore strategies to increase their effectiveness as tools for teaching about evolution and the relationships among taxa.

Visitors may encounter a wide range of tree graphics in museums, even within a single institution (Diamond and Scotchmoor 2006; MacDonald and Wiley 2012). These graphics vary in orientation, geometry, design, and representation of time. Although it is commonly assumed that graphical displays are immediately and intuitively understood, this is not the case (e.g., Hegarty and Stull 2012; Petre and Green 1993; Yeh and McTigue 2009). Thus, it is important for museum exhibit designers and curators to understand how people interpret depictions of evolutionary relationships so they can create tree diagrams that effectively communicate scientific principles to public audiences.

In 2008, a group of museum professionals and learning researchers, led by Teresa MacDonald, Judy Diamond, and David Uttal, established the Understanding the Tree of Life (UToL) project. This effort brought together museum practitioners, learning researchers, and evolutionary scientists to develop best practices for displaying and teaching the Tree of Life. The three-year project culminated in a conference attended by 62 professionals from 30 partner institutions, including museum directors, exhibit developers, educators, and other museum staff; learning researchers; and evolutionary biologists. The goals of the conference were to explore a process of tree exhibit design that reflects learning research and to develop recommendations for the broader museum community. This goal, to develop what the recent National Academies report on informal education (National Research Council 2009b, p. 305) referred to as an "interdisciplinary community of scholars and educators" focused on practice, is crucial to improving learning in informal environments.

The conference was designed to help museum professionals link learning research to exhibit practice. Often exhibits are designed according to past practices, a developer's sense of how best to communicate ideas, or curators' notions of acceptable scientific presentation. The UToL project proposed that an additional consideration in the development of exhibits should be an understanding of how people reason in response to graphical depictions of the Tree of Life. In support of this goal, the project included four pilot studies that examined how both children and adults understand depictions of the Tree of Life, the results of which were presented early in the conference: (a) Can children read trees? (Ainsworth and Saffer 2013); (b) Phylogeny exhibits and understanding geological time (Dodick and Aharonson); (c) Treethinking: Do pictorial representations of evolution help or hinder museum visitors' understanding? (Evans, Frazier, Hazel, Kiss, Lane, Spiegel, and Diamond); and (d) Learning to understand the Tree of Life (Matuk and Uttal 2011). Groups of museum professionals and learning researchers then used these findings, the results of additional psychological research that was part of the researchers' expert knowledge, and the practitioners' extensive experience with museum visitors to review the strengths and weaknesses of five trees currently or recently on display in museums around the United States. Based on these discussions, the groups made recommendations for the redesign of the trees.

In the remainder of this article, we first describe the five trees discussed by the working groups. We then summarize the themes that emerged from the collaborative tree review process and provide an in-depth discussion of how one particular tree might be redesigned. These latter discussions are organized around six principles for effective tree design that were extracted from the psychological research literature. These principles provide an organizational framework for common themes that emerged from the collaborative tree review process.

\section{Five museum trees}

The five trees were chosen by the conference organizers to be representative of the different ways tree diagrams are used in museum graphics. The conference organizers wanted to include exhibit graphics that were influential, considered significant by the museum field, and varied in their content (i.e., taxa included) and presentation style. Four of the trees are cladograms, which depict evolutionary relationships among taxa in a branching format in which two branch tips that share the most immediate branching point (or node) are most closely related. Although cladograms depict patterns of most recent common ancestry, relationships are supported by character evidence at the branching points rather than by putative ancestors. The fifth tree includes both branching and linear components, thereby enabling identification of certain species as proposed ancestors of other species.

All five examples are simple bifurcating trees that focus either exclusively or primarily on eukaryotes. Such trees do not represent all possible patterns of diversification. Particularly among Eubacteria and Archaea, mechanisms such as horizontal gene transfer, hybridization, and lineage merger events mean the inheritance of traits is sometimes reticulate, a pattern that is better represented by a network. There is an ongoing debate among scientists about whether reticulation means that the Tree of Life hypothesis is falsified, obsolete, or should be restricted to a subset of taxa (e.g., Bapteste et al. 2009; Doolittle and Bapteste 2007) or whether the Tree remains the best explanation of the graded similarity of all life (e.g., Lienau and DeSalle 2009; Mindell 2013). As 
Mindell (2013) describes in his thoughtful discussion of the multiple uses of the Tree of Life, reticulate evolution has long been known and accepted as a pattern within the Tree of Life, and the core feature of the Tree, phylogenetic relatedness, remains a valid organizing principle for biological diversity. Although the Tree may provide a simplistic representation of some evolutionary relationships, it is important as a metanarrative to explore life's common descent. Because the vast majority of museum exhibits concern eukaryotes or, if Eubacteria and Archaea are included, their inclusion is limited to the Domain level, we did not discuss diagrams that represent reticulate patterns of diversity.

\section{Succulent plants}

The succulent plants tree (see Figure 1) was part of a temporary exhibition, Travels in the Great Tree of Life, that was on display from 2/16/08-2/28/09 at the Yale Peabody Museum of Natural History. The exhibition's primary learning goal was to explain the nature of the evolutionary relationships that form the basis for the Tree of Life. Across seven sections, it explored the importance and monumental scientific challenge of understanding these relationships. The exhibition included live animals and plants, specially commissioned films and animations, an interactive game, and museum specimens.

This particular tree, a cladogram, was part of the exhibit section that dealt with convergence-the independent development of similar adaptations to similar environments-which is an important topic in understanding the evolutionary relationships among taxa. The tree illustrates that thick succulent stems (an adaptation to dry conditions) evolved independently in several lineages of desert flowering plants. Also included in the diagram are close relatives of each group that have leaves, two familiar plants that are very different in appearance to one another, and unlabeled branches intended to represent the fact that there are many taxa between those that are explicitly labeled on the tree. The graphic panel included a verbal explanation of this example of convergence and was placed inside a case with living examples of the taxa. On the wall nearby was a large sign that explained the nature of convergent evolution.

\section{Arthropods}

The arthropod tree at the Harvard Museum of Natural History (see Figure 2) represents the most numerous group of taxa on Earth and is part of a major gallery, Arthropods: Creatures that Rule, that opened in 2006. This large cladogram spans 24 feet in width and consists of a 3-dimensional branching metalwork structure affixed to a floor-to-ceiling mural featuring the major groups of living arthropods. At the branch tips are specimens and color photographs of each taxonomic group. Distinct colors and associated icons are used to identify lineages and hypothetical common ancestors. Supporting interpretive graphics rest on a raised platform at the base of the tree. The arthropod tree exhibit was developed as a tool to introduce a middle school to adult-aged public audience to current scientific thinking about evolutionary relationships among arthropods-specifically, to help visitors understand the characteristics that distinguish arthropods from other animals, the characteristics that define

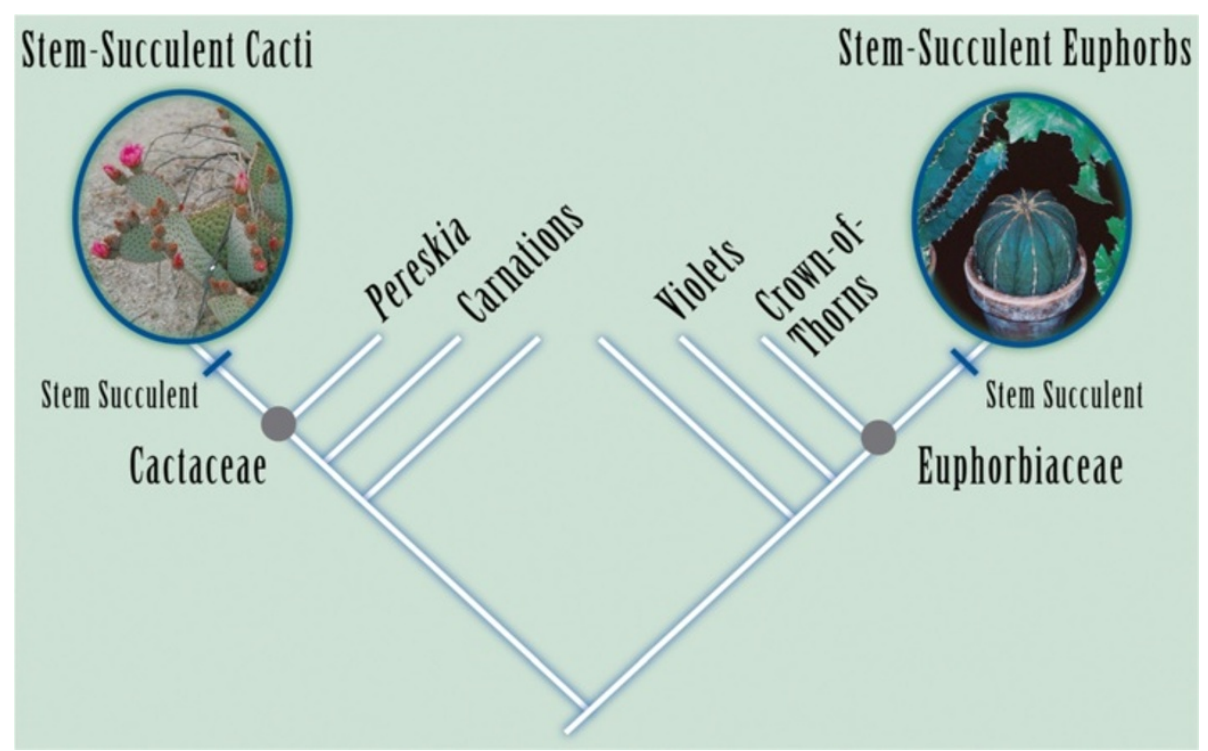

Figure 1 A Succulent Convergence, Travels in the Great Tree of Life exhibit, courtesy of the Yale Peabody Museum of Natural History, photograph by Sally Pallatto. Reprinted with permission. 


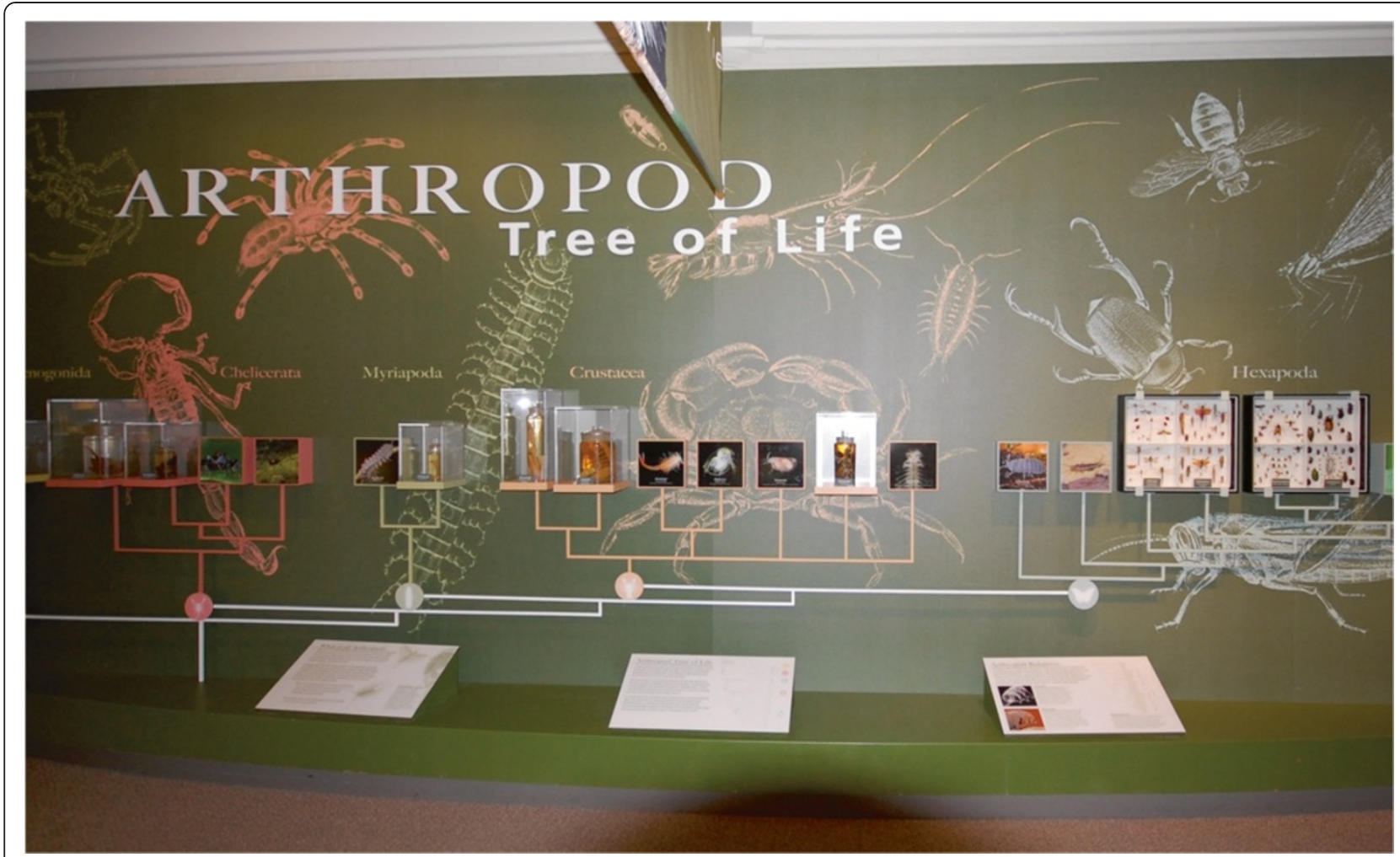

Figure 2 Arthropod Tree of Life, Arthropods: Creatures That Rule gallery, courtesy of the Harvard Museum of Natural History, photograph by HMNH Exhibit Department. Reprinted with permission.

major groups of arthropods, and how arthropods "fit" into the larger Tree of Life. The design of the exhibit was also shaped by universal design considerations, especially those that address the visual accessibility of the real arthropod specimens incorporated into the display. For example, the tree was vertically compressed to enable the specimens to be within easy viewing height.

\section{Dinosaurs}

The dinosaur tree at the Carnegie Museum of Natural History (see Figure 3) is part of an interactive touchscreen exhibit located at the front of each of a set of tableaux of dinosaur specimens in the permanent hall, Dinosaurs in their Time, which opened in 2007. This complex tree, a cladogram, shows all groups within Dinosauria. It provides a hierarchical presentation through a series of animated steps that zoom in from a large tree to its individual components. Its primary purpose is to show how the dinosaur highlighted in the particular exhibit section is related to other dinosaurs in the Hall, with the animation progressively focusing the screen to reach the relevant family of dinosaurs. The viewer can pause, forward, or reverse through the animation. At the end of the cycle, it is possible to learn more about the specific dinosaur by accessing further information through the touchscreen.

\section{Circular tree of life}

The circular tree of life (see Figure 4) is part of the Boston Museum of Science's permanent exhibit, Human Body Connection, in the section on human evolution that opened in 2005. This tree, a cladogram developed by David Hillis and colleagues at the University of Texas at Austin, represents 3,000 species from across the Tree of Life and attempts to convey the enormity of the Tree in a way that is almost impossible in a linear format. The tree graphic is roughly four feet in diameter and can be rotated by the visitor to view different tips under a stationary magnification device. Seven of the model taxa that appear elsewhere in the exhibit, including humans, are highlighted in the tree. The main learning goals of the exhibit are to show that all life has a common ancestor, to show that the Tree of Life functions as another representation of the evolutionary timeline that additionally emphasizes biodiversity, and to address the misconception that evolution is a progression to perfection. Visitors are encouraged to follow the lines back to the center of the tree to discover how each highlighted taxon is related to humans through common ancestry.

\section{Hominids}

The hominid tree from the American Museum of Natural History (see Figure 5) represents current scientific information 


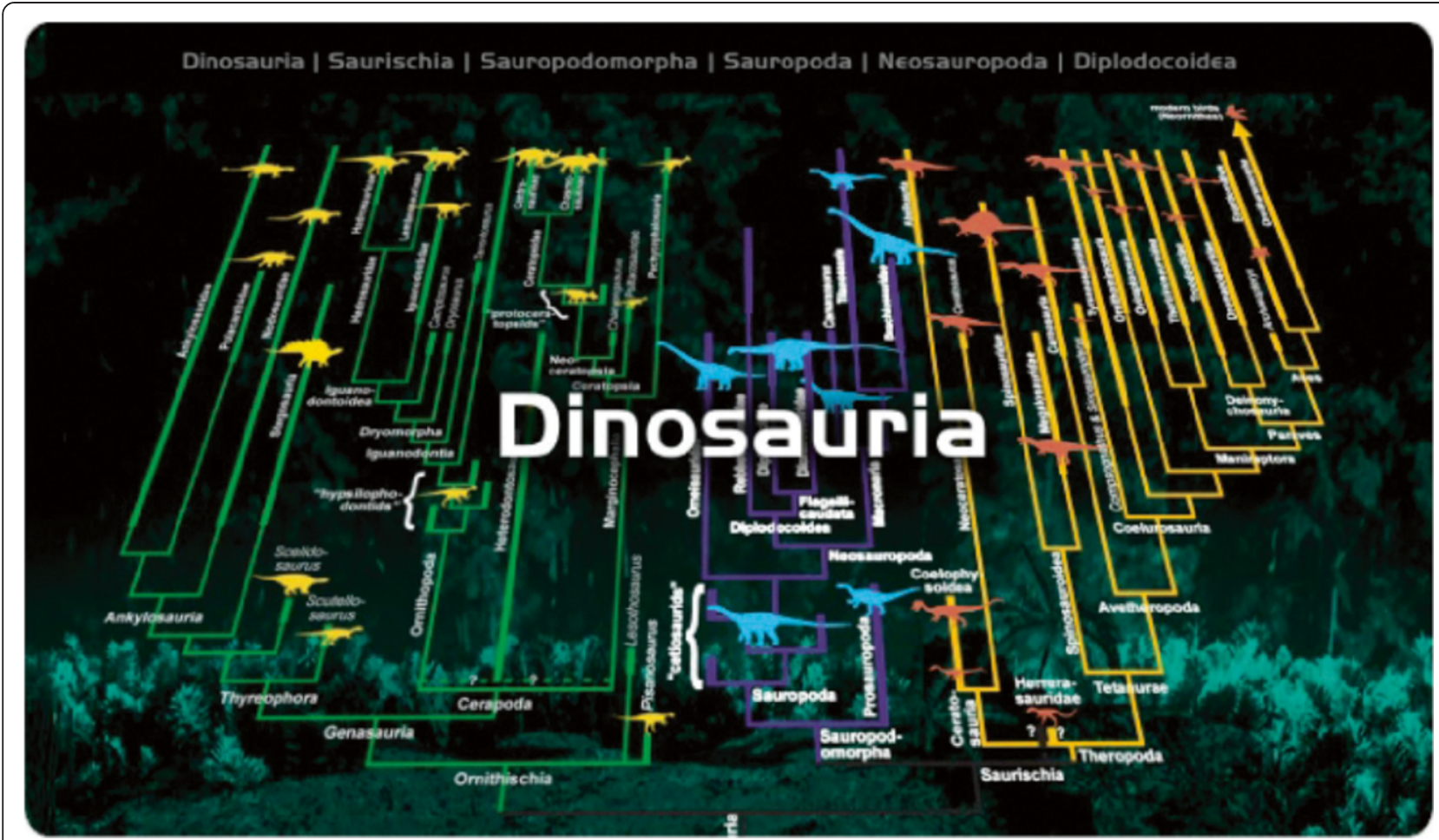

Figure 3 Dinosauria Tree, Dinosaurs In Their Time gallery, courtesy of the Carnegie Museum of Natural History. Reprinted with permission.

on probably the most contentious aspect of the theory of evolution in American society. It is a component of a permanent exhibit gallery, the Ann and Bernard Spitzer Hall of Human Origins, that opened in February 2007. This large graphic (nearly 6 feet high) depicts a timeline of 23 hominid species, showing the range of time that each one is known to have existed based on fossil evidence. This is the only tree considered here that is not a cladogram. It is in the first of five sections of the Hall, which places hominids in the context of both the Tree of Life and primate phylogeny. The content of the exhibit focuses on several key ideas including: (1) Humans are the only remaining descendants of a large group of primates, (2) the evolution of humans is not the result of a lineal history in which each successive species replaced one that came earlier, and (3) this tree represents the current hypothesis of human evolution and, like all scientific hypotheses, may change based on new evidence (e.g., new fossil finds, new analyses of existing fossils).

\section{Guiding principles for depicting the tree of life}

Each of the five trees was developed as one component of a larger exhibit designed to engage visitors in learning about the evolutionary relationships among a set of taxa (i.e., species or higher-order groups of species). Discussions of these trees at the conference identified common aspects of diagram comprehension and human learning that should be carefully considered when developing Tree of Life displays to help support visitor engagement and understanding. In this section, we discuss six principles derived from the research bases in cognitive, developmental, and educational psychology. For each principle, we compare two or more trees that vary in how effectively they follow that principle. We then describe how we redesigned the succulent plants tree in accordance with the principle under consideration.

\section{Use graphic formats that facilitate appropriate} interpretation and counteract inappropriate interpretive biases

We consider three issues in this section. Two apply to diagrammatic depictions of evolutionary relationships generally; the third is specific to depictions of hominid evolution. Graphic representations of the Tree of Life belong to the category of schematic diagrams, in which diagrammatic elements and the spatial relations among them metaphorically convey meaning (Hegarty et al. 1991). For example, lines seem naturally suited to represent connections (e.g., relationships) or motion, and circles seem naturally suited to represent objects or locations (Tversky et al. 2000). When information is mapped onto diagram components in accordance with these natural affordances, people are faster and more accurate at drawing appropriate inferences (e.g., Hurley and Novick 2010). 


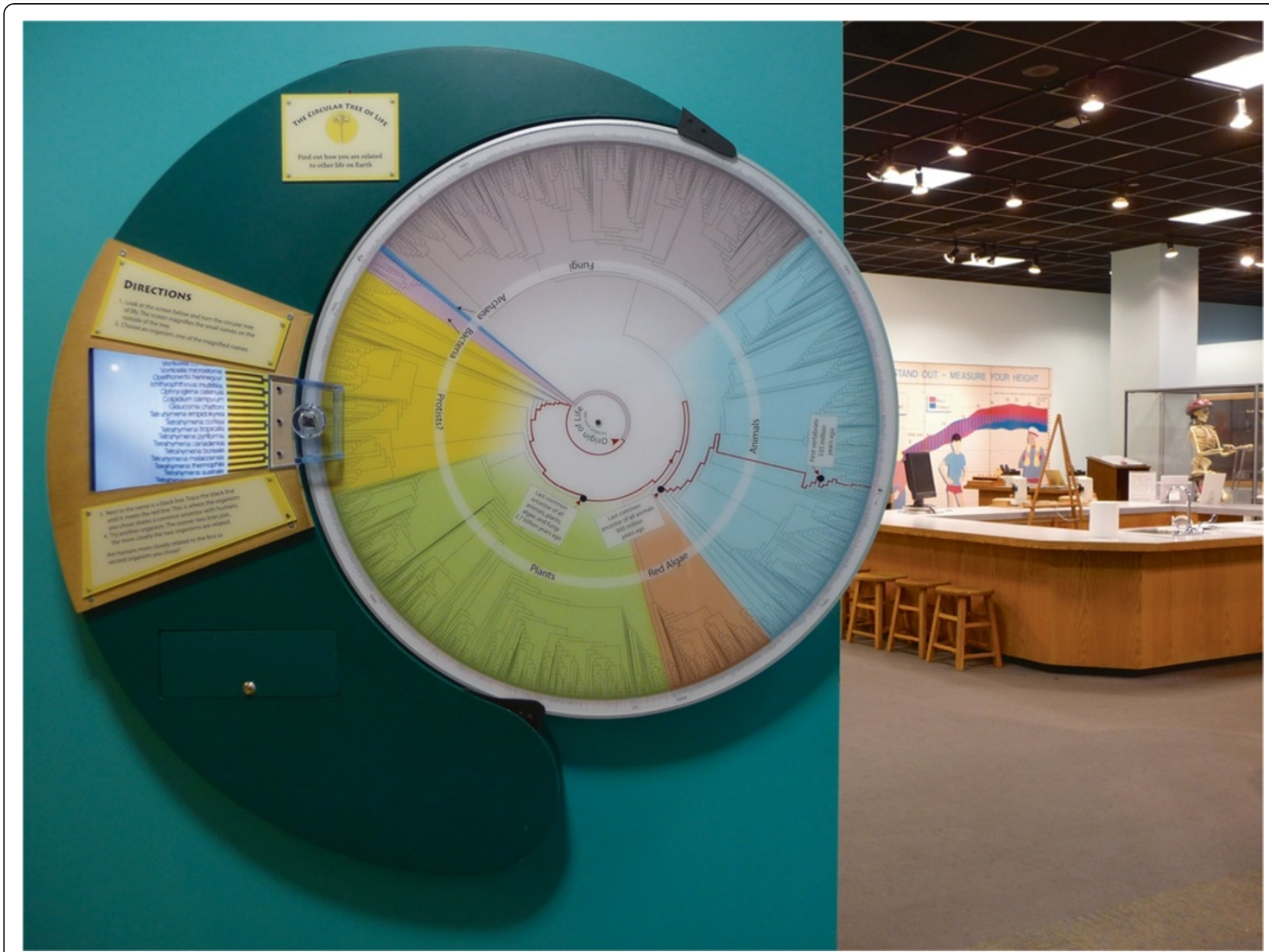

Figure 4 Tree of Life, Human Body Connection gallery, courtesy of the Museum of Science, Boston. Authors of circular tree graphic: David M. Hillis, Derrick Zwickl, and Robin Gutell, University of Texas at Austin. Reprinted with permission.

A large body of research within psychology has investigated how people visually scan, extract meaning from, and interpret a variety of different kinds of diagrams. Recently, some of this research has considered how both children and adults interpret evolutionary histories of taxa depicted in a variety of formats (e.g., Ainsworth and Saffer 2013; Catley et al. 2013; Meir et al. 2007; Novick and Catley 2013; Novick et al. 2011b). This research shows that even nine-year-olds can learn to extract basic information from tree diagrams in about 10 minutes (Ainsworth and Saffer 2013).

Novick and Catley (2007; 2013; Catley et al. 2012) compared college students' interpretations of cladograms in the rectangular format like that used for the arthropod tree (Figure 2) versus in the diagonal format like that used for the succulent plants tree (Figure 1). Using a variety of tasks and questions, they found that students did much better with the rectangular format, even after relevant instruction in phylogenetics (the science of identifying and understanding evolutionary relationships among Earth's biota). Two factors are responsible for this finding. First, adults have a good understanding of the structure of rectangular-format hierarchies in nonevolution contexts because of the variety of such diagrams they have encountered in both popular culture and other academic subjects (Novick 2001). Moreover, even children as young as seven understand the structure of simple (rectangular format) hierarchies (e.g., Greene 1989). Second, a basic principle of perception (the Gestalt principle of good continuation; Kellman 2000) leads people to interpret a continuous line as a single entity. In the diagonal cladogram format, most continuous lines represent multiple branching points, but people tend to interpret them as if no branching has occurred because of good continuation. Thus, our first redesign of the succulent plants tree is to redraw it in the rectangular format (see Figure 6).

Another recent study found that college students interpret the nature of speciation differently depending on whether the evolutionary tree depicts the taxa arranged 


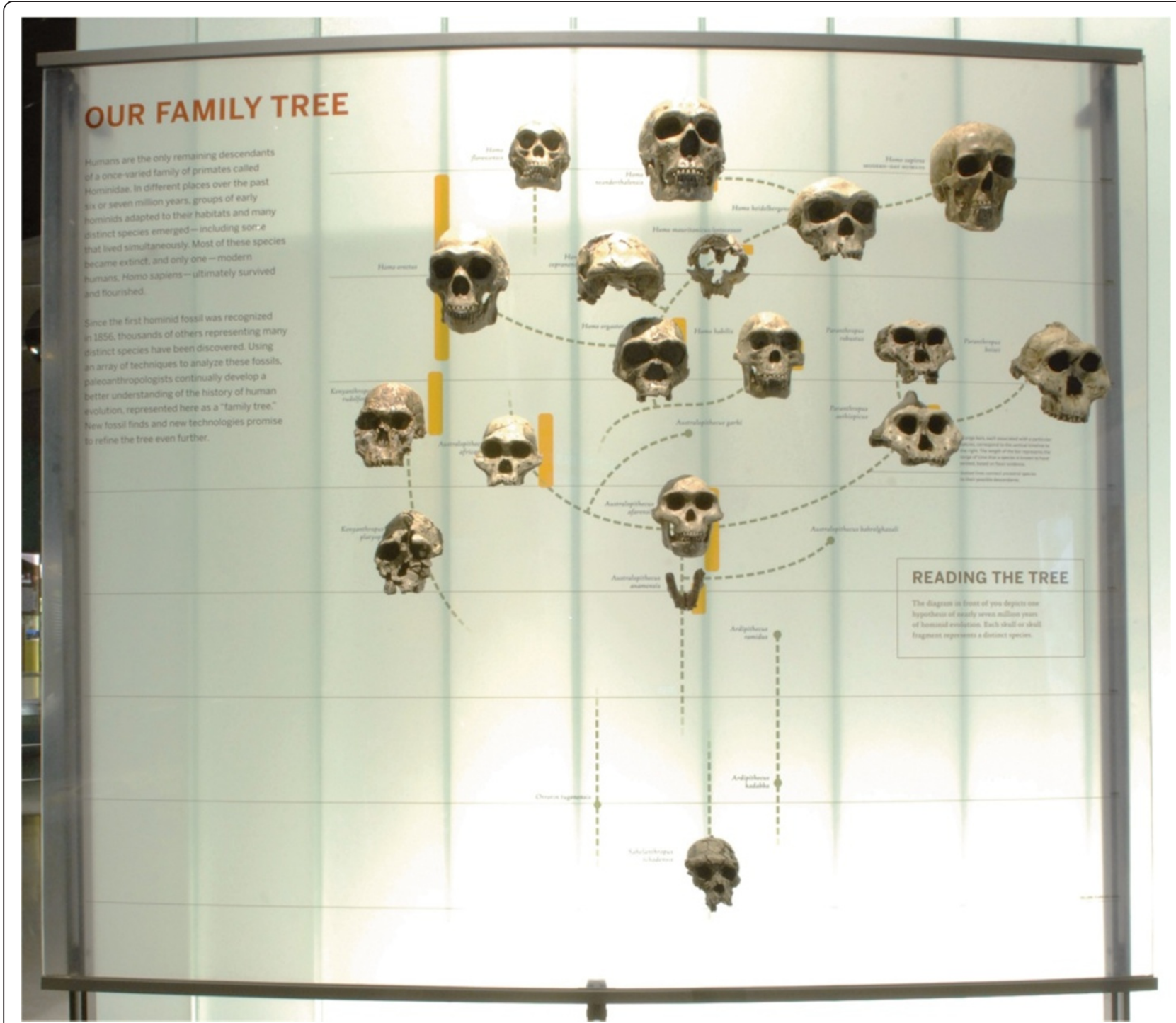

Figure 5 Family Tree Exhibit, Hall of Human Origins, courtesy of the American Museum of Natural History, photograph by AMNH/D.

Finnin. Reprinted with permission.

in a linear sequence along a single branch, as in parts of the hominid tree (Figure 5), or in a branching (cladogram) format, as in the other trees discussed here. In particular, when the diagram included linear sequences, students were more likely to talk about one (hominid or horse) taxon turning into or becoming another (hominid or horse) taxon over time (Novick et al. 2011b). This interpretation in terms of anagenesis, or transformation, is contrary to the accepted explanation of speciation within evolutionary biology, which is cladogenesis, or branching (e.g., Futuyma 2013). These results from the psychological literature are consistent with findings from museum studies that visitors typically interpret exhibits on human evolution as depicting the evolution of our species as linear, directional, and progressive (Scott 2007, 2010). The view of evolution as a process of transformation unintentionally reinforces ideas of teleology (design) and progression. For trees that include primates, it also inappropriately reinforces anthropocentrism (Catley and Novick 2008; MacDonald and Wiley 2012) and the intuitive explanation that evolutionary change is analogous to developmental change across childhood (Evans et al. 2010). Redrawing the hominid tree to avoid linear sequences would not only curtail anagenetic (transformational) interpretations of hominid evolution, but it also would support the verbal message in the exhibit that hominid evolution did not have a linear history.

The third issue we consider in this section is the location of Homo sapiens in trees that depict hominid evolution. H. sapiens is commonly found in the top-right position, as in the hominid tree (Figure 5). This location has the potential to reflect and reinforce ideas of 


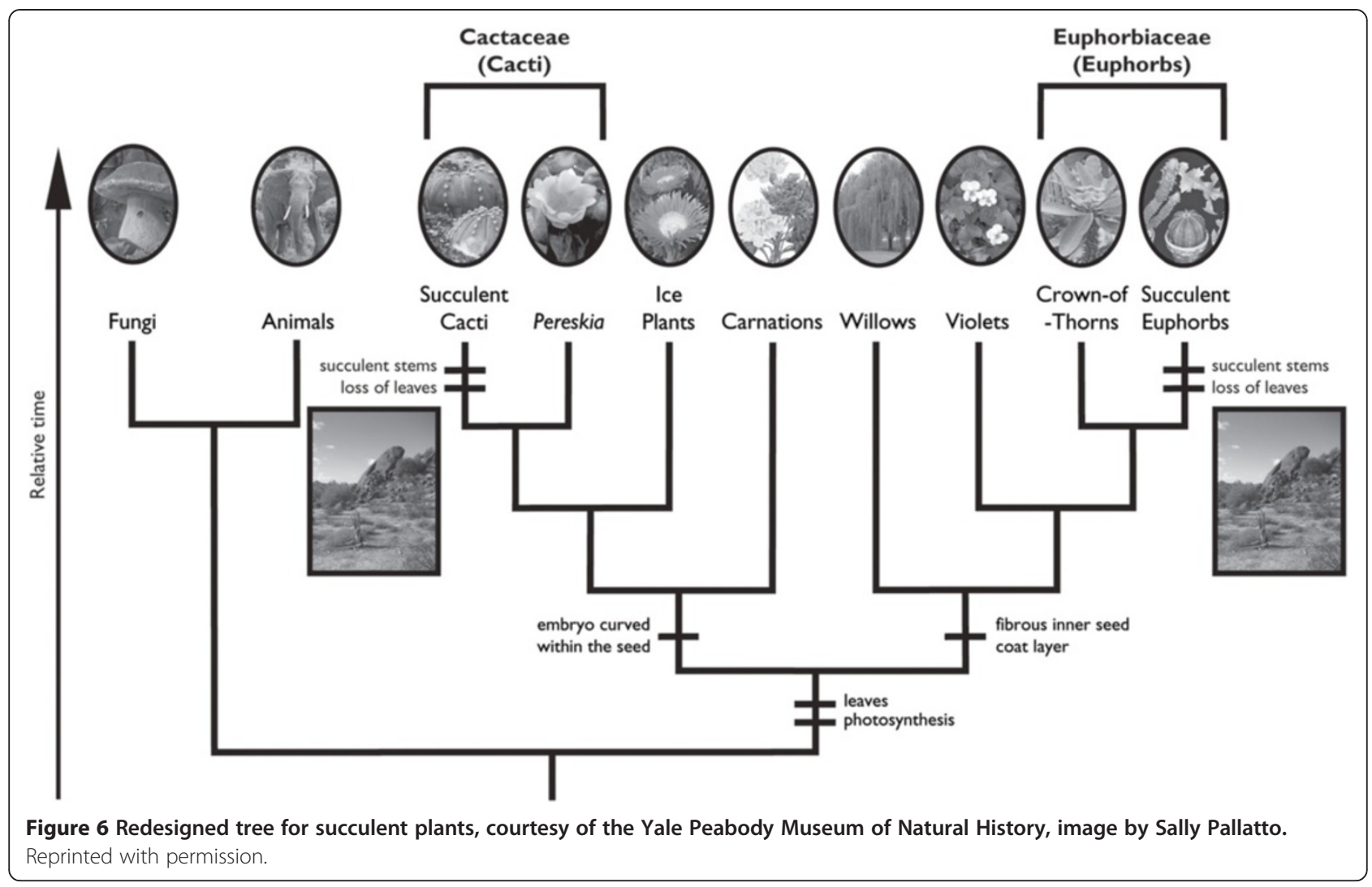

teleology and progression (Matuk 2007; Sandvik 2009), with humans being viewed as the privileged species (Evans 2001). A recent study of the impact of taxa placement in cladograms found that college students were more likely to provide teleological responses when humans were located at the top or right end rather than in a central location with other taxa on either side (Phillips, Novick, and Catley unpublished data). Given this result, as well as the fact that visitors often use intuitive reasoning outside a formal education environment (Evans et al. 2010), it would be preferable for $H$. sapiens to occupy a central position in trees that depict relationships among that taxon and other hominids (or other taxa more generally), as was done in the Explore Evolution exhibit (Diamond et al. 2005). This principle also extends to the placement within the tree of broader taxonomic groups that include humans (e.g., mammals).

\section{Include characters on cladograms to indicate the} scientific basis for the branching structure depicted

Characters shared by a group of taxa due to descent from a most recent common ancestor (i.e., synapomorphies) constitute the evidence to support the nested structure of a given cladogram. Novick et al. (2010) found that including such characters on trees was critical to undergraduate students' ability to understand the structure (i.e., branching pattern) of the depicted phylogenies. Likewise, Ainsworth and Saffer's (2013) study points to the importance of synapomorphies in influencing children's understanding of cladograms. Although similar work has not been carried out in an informal education setting, it is reasonable to assume that highlighting and labeling key characters used to support the branching pattern shown would be beneficial. This was a common theme in all five of the working groups' discussions, triggered by the fact that none of the trees had complete labeling of shared characters, and in some cases there were no characters at all. The use of characters would highlight and build on visitor interest in morphological features of different taxa in a tree (Giusti and Scott 2006). We should note, however, that graphic space constraints and the difficulty of finding characters supporting each group that can be easily explained to a lay audience present challenges to including characters on museum trees.

In our redesign of the succulent plants tree (Figure 6), we negotiated these trade-offs by only including characters to support three critical groups: (1) The possession of leaves and the ability to photosynthesize are synapomorphies for plants, distinguishing those taxa from the opisthokonts (fungi and animals); (2) an embryo curved within the seed is a synapomorphy for the group one level up in this tree that includes cacti; and (3) a fibrous inner seed coat layer (exotegmen) is a synapomorphy for the group one level up that includes euphorbs. The 
characters noted in (2) and (3) provide part of the explanation for why succulent cacti and euphorbs are not closely related.

We also included succulent stems and loss of leaves as convergently-evolved shared characters for the succulent cacti and euphorbs. This addition is important for two reasons. First, it reinforces information currently only noted in the accompanying text, and integrating textual and diagrammatic information has been found to improve learning (e.g., Sweller et al. 1998). Second, it provides visitors with an implicit contrast between two types of shared characters for the succulent cacti and euphorbs-photosynthesis reflects common ancestry, whereas succulent stems reflect convergent evolution.

\section{Provide opportunities to create cognitive dissonance in viewers and encourage self-explanation}

Images can be designed that challenge viewers to question the content and therefore construct their own explanations, which are cognitive processes that encourage learners to build understanding (e.g., Chi et al. 1989; Ainsworth and Loizou 2003). The arthropod tree (Figure 2) appears to have been effective in this regard as visitors expressed that the display caused them to question their preconceived notions of animal relationships (Reinfeld 2010). Many were surprised and intrigued by the connections they saw and curious to explore the new ideas it evoked. To encourage self-explanation in the redesigned succulent plants tree (Figure 6), we placed images of the critical environmental context (a desert) next to the branches leading to the succulent cacti and euphorbs and immediately below the characters that were selected for by that environment. This may encourage viewers of the redesigned diagram to think about the conditions under which similar characters can arise independently, leading to convergent evolution. Seeing that both succulent cacti and succulent euphorbs evolved in similar desert environments, for instance, provides an opportunity for viewers to consider the role of common selective pressures in convergent evolution.

Situating H. sapiens in a middle position between other taxa, as suggested earlier, may promote useful questioning and self-explanation concerning hominid evolution. If humans are not found in the expected location at the "endpoint" of evolution, viewers might reconsider their misconception (Evans 2001) that our own species did not arise through the same biological mechanisms as are responsible for the appearance of all other species on Earth.

\section{Use different modes of communication to their respective advantages}

Because different media are suited for communicating different kinds of information (e.g., Najjar 1998), exhibit developers should work to match the medium with the message. For example, psychological research indicates that pictures are better recognized and recalled than verbal labels (e.g., Nelson et al. 1976; Paivio and Csapo 1973). In addition, they can show many aspects of a situation or object simultaneously. Thus, pictures can communicate certain kinds of information more efficiently than linear, verbal formats, from which information must be extracted sequentially. For example, the pictures at the tips of the succulent plants tree (Figure 1) directly illustrate the main message that the succulent cacti and euphorbs look very similar despite being distantly related. One change we made to this tree (Figure 6) was to provide a picture of each of the named taxa to supplement and reinforce the corresponding additional message in the accompanying text that taxa that are closely related need not look alike (e.g., succulent cacti and Pereskia, crown-of-thorns and succulent euphorbs). In addition, we added pictures and names of taxa to the unlabeled branches because recent research suggests that naïve viewers are not likely to interpret the message of those branches as intended, which is that there are many taxa between the groups shown on the diagram (Novick and Catley 2007).

An object-based experience can help to guide or mediate visitors' attitudes, perspectives, and relationship with the content (National Research Council 2009b). The arthropod tree (Figure 2) was designed to make use of and physically accommodate real specimens of all taxa large enough to show. Visitors are drawn to the objects on the tree and from there move out to look at how they connect to others. In the hominid tree (Figure 5), the inclusion of skull casts provides a level of resolution, density of information, and authenticity that are not possible with two-dimensional representations (Leinhardt and Crowley 2002). The use of these touchable casts both documents the scientific evidence and provides an engaging visual and tactile experience for visitors. Interactivity has the potential to significantly enhance visitor understanding and engagement (e.g., Allen 2005) and can certainly be effective in tree displays.

Another type of communication tool that can be effective in certain circumstances is animation (e.g., see Tversky et al. 2002). The dinosaur tree (Figure 3) uses this tool to move successively though the major groups of taxa, thus allowing users to see how the highlighted dinosaur fits into a broader evolutionary context. In general, animation is a representationally economical way of showing an item's location in a larger context. For evolutionary trees, the animation would also have the benefit of forcing viewers to scan the tree from the bottom to the branch tips, that is, in the direction of the implicit time arrow and thus along the appropriate evolutionary path leading to the taxon of interest. The effectiveness of this tool in the dinosaur tree is compromised, however, 
because (1) the animation moves very quickly from the full tree to the zoomed-in image, making it difficult to process all the information one is seeing, and (2) although it is possible to pause the animation, this feature of the exhibit is not clearly communicated. The ability to pause an animation has been found to be a key feature supporting its effectiveness (Tabbers and de Koeijer 2010).

\section{Indicate the relationship of individual trees to the broader tree of life}

The entire Tree of Life represents all present and past biodiversity on Earth and is thus unimaginably large and complex. The number of formally described species is more than 1.5 million, and estimates of the total number of living species range from 3.6-100 million (Wilson 2004). The latter estimates do not include extinct species. Of the five trees considered here, only the circular Tree of Life (Figure 4) gives some sense of this complexity due to its depiction of the relationships among 3,000 species. Offsetting this advantage of the circular tree is the obvious difficulty of extracting specific information about the relationships among a subset of taxa of interest from this representation. In addition, this tree still follows a bifurcating model, and, as discussed earlier, does not represent the reticulate nature of evolution in some groups represented, especially the prokaryotes.

One way to help museum visitors understand that any particular tree included in an exhibit is merely a small portion of a more comprehensive Tree of Life is to include a separate, small reference cladogram next to each exhibit tree that includes key taxonomic groups, along with some visual indication of where in this reference cladogram the exhibit tree is located. This is a common strategy adopted by college biology textbooks (Catley and Novick 2008). In addition to providing a context for each individual tree display, the repetition of taxa across trees within an exhibit would reinforce viewers' understanding of their individual evolutionary histories.

Adding a second diagram, even if it is small, to each sign may be challenging due to space constraints, however. Moreover, viewers would have to integrate information across two diagrams, which could be difficult without a supporting explanation. Another way to accomplish the goal at hand is to repeat key reference taxa (e.g., bacteria, plants, animals, fungi) as part of each exhibit tree. Although this solution avoids the drawbacks of adding a separate reference tree, it may be less effective at highlighting the fact that any particular tree is a subset of the comprehensive Tree of Life.

None of the exhibit trees examined here that focus on a constrained subset of taxa (plants, arthropods, dinosaurs, hominids) provides any indication of how that tree relates to the larger Tree of Life. We do not take a position here on which strategy for accomplishing this goal is best as the answer likely depends on the nature of the exhibit and its context. Moreover, given the freechoice environment of museum exhibits, each section needs to be interpretable on its own as much as is feasible (National Research Council 2009b). Because the Tree of Life is such an important concept in contemporary science, it is important to help visitors understand how individual trees are situated within the full Tree of Life. We therefore urge exhibit developers to give careful consideration to adopting one of the strategies for accomplishing this goal described here.

Consider how the succulent plants exhibit could be redesigned in each of these ways. Many people fail to realize that fungi (e.g., mushrooms) are more closely related to animals than to plants, and many incorrectly believe that fungi are in fact plants (e.g., Hampton 1988; Novick et al. 2011a). Thus, one useful reference cladogram could be a simple three-taxon tree showing that fungi and animals are more closely related to each other than either is to plants. This cladogram could be presented next to the succulent plants tree, as well as next to other trees that include animal or fungal taxa. An alternative approach, illustrated in Figure 6, is to add fungi and animals to the existing succulent plants tree. Note that we added the group Animalia on the left side of the tree to address the teleological interpretive bias mentioned earlier that can result from placing groups that include humans in the rightmost location.

\section{Incorporate some indication of time in the tree representation}

A sizable body of research indicates that both children and adults have difficulty understanding deep time (e.g., Catley and Novick 2009; Dodick and Orion 2003; Trend 1998), the idea that Earth's geography and biodiversity are the products of geological and evolutionary processes that have occurred over several billion years. Adults and adolescents also misunderstand how time is mapped onto a phylogenetic tree, often thinking that time goes from left to right across the branch tips or from the branch tips to the root of the tree (Dodick and Aharonson, unpublished data; Meir et al. 2007). In fact, however, time goes from the base to the branch tips (except in a circular tree, in which it goes from the center of the circle to the perimeter). Given this discrepancy between scientific convention and viewer interpretation, it is important to consider how time is indicated in the five trees examined here.

The circular (Figure 4) and hominid (Figure 5) trees are the only ones to indicate time explicitly. In the circular cladogram, the center of the tree notes the origin of life 3.6 billion years ago, three internal nodes are labeled with the time at which a particular event occurred (e.g., last common ancestor of all animals 900 million years 
ago), and the outer perimeter is labeled today. Although the hominid graphic includes a geological timeline pictured in the background to the right of the tree, it uses very small text and is indistinct. This may make it less noticeable, thereby decreasing the likelihood that visitors will use it in their interpretations of the exhibit.

The hominid tree also provides an implicit indication of time, which visitors could extract if they make the effort to coordinate the verbal information provided in the display's labels - that humans are the only extant hominid because all other hominid species became extinctwith the spatial information provided in the tree- $H$. sapiens is located at the top right, whereas other hominid species are mostly located lower in the tree. Some information about relative time might also be extracted from the dinosaur tree (Figure 3) because the branches for different dinosaurs terminate at different heights, representing extinction at different points in time. Of course, people do not always extract information that is represented only implicitly, especially in the absence of a compelling reason to do so. The succulent plants (Figure 1) and arthropods (Figure 2) trees do not include any representation of time.

In accordance with the principle noted earlier that integrating textual and diagrammatic information improves learning (e.g., Sweller et al. 1998), several working groups suggested including some type of explicit representation of time on museum trees. Preliminary results of Dodick and Aharonson's unpublished research indicate that including very basic temporal clues helps direct viewers' attention toward the interior of the tree so they do not read the tree across its external tips, which is a common problem among lay observers (e.g., Baum et al. 2005; Meir et al. 2007).

An important decision that needs to be made in this regard is whether the representation of time is absolute or relative. Although representing absolute time would provide the most precise information for museum visitors, there are several drawbacks. One is that for most evolutionary events, scientists are not able to provide the date at which the event occurred. A second drawback is that it can be difficult to clearly show the branching structure of the tree if the tree covers a wide range of time and some of the time intervals are close together. Although this problem can be ameliorated by using a logarithmic time scale, there are issues concerning museum visitors' understanding of this scale. For these reasons, we suggest incorporating a simple representation of relative time for most trees. For example, in our revision of the succulent plants tree (Figure 6), we added an arrow to show that time runs from the bottom of the tree to the top. Of course, if the time range is small enough and relatively precise dates are known, a representation of absolute time could be very informative.

\section{Conclusions}

Curators, exhibit developers, and graphic designers strive to find an appropriate balance between scientific content and creating an accessible and effective design to achieve the desired learning goals. In this article, we considered the issue of effective design for phylogenetic or evolutionary trees, which are increasingly important parts of exhibits on biodiversity and evolution (MacDonald and Wiley 2012). Trees can address multiple learning goals, such as understanding relatedness among the diversity of life on Earth, appreciating the size and complexity of the Tree of Life, and realizing the immensity of geological time. Museum studies indicate that visitors are very interested in learning how different species are related to each other (Giusti 2008; Reinfeld 2010).

The thesis of the present article is that museums need to seriously consider and incorporate the results from cognitive, developmental, and educational psychology research when designing tree graphics, even as they attend to visitor engagement and enjoyment (National Research Council, 2009b). This research is important because, contrary to popular belief, graphical displays do not immediately and directly convey their intended meaning (Hegarty and Stull 2012; Petre and Green 1993; Yeh and McTigue 2009). We distilled the psychological research base into six guiding principles for depicting the tree of life in museum exhibits: (1) Use diagram formats that facilitate appropriate interpretation and counteract inappropriate interpretive biases; (2) include characters on cladograms to indicate the scientific basis for the branching structure depicted; (3) provide opportunities to create cognitive dissonance in viewers and encourage self-explanation; (4) use different modes of communication to their respective advantages; (5) indicate the relationship of individual trees to the broader Tree of Life; and (6) incorporate some indication of time in the tree representation.

The Tree of Life is revolutionizing our understanding of Earth's biodiversity and having considerable impact on research and practices in human health, agriculture, and the preservation of the environment (e.g., American Museum of Natural History 2002; Freeman 2011; Futuyma 2004; Yates et al. 2004). Indeed, biology's tremendous potential for solving numerous contemporary problems rests on the fact of evolution (National Research Council 2009a). It is crucial, therefore, for the general public to have a basic understanding of evolution and of the Tree of Life to comprehend and address these issues. With attention both to traditional factors that influence the design of museum exhibits and to psychological research on how people understand diagrams in general, and Tree of Life diagrams in particular, museums can play a leading role in fostering a scientifically literate 21 st century citizenry. 


\section{Competing interests}

The authors declare that they have no competing interests.

\section{Authors' contributions}

All authors have read and approved the final manuscript.

\section{Acknowledgements}

This manuscript is based on working group discussions at the Understanding the Tree of Life conference that took place in August 2010 at the Carnegie Museum of Natural History. The authors thank Sam Taylor, Director of the Museum, for hosting the conference, and all of the conference participants for their valuable contributions to the discussions. The conference was supported by a grant from the National Science Foundation (\#0715287) to the University of Kansas. Any opinions, findings, and conclusions or recommendations expressed in this material are those of the authors and do not necessarily reflect the views of the National Science Foundation.

\section{Author details}

'Department of Psychology \& Human Development, Vanderbilt University, 230 Appleton Place, Peabody College \#552, Nashville, TN 37203-5721, USA. ${ }^{2}$ Harvard Museums of Science and Culture, Cambridge, MA, USA. ${ }^{3}$ University of Kansas Natural History Museum, Lawrence, KS, USA. ${ }^{4}$ University of Nebraska State Museum, Lincoln, NE, USA. ${ }^{5}$ University of Nottingham, Nottingham, UK. ${ }^{6}$ American Museum of Natural History, New York, NY, USA. ${ }^{7}$ Western Carolina University, Cullowhee, NC, USA. ${ }^{8}$ Science Teaching Center, The Hebrew University of Jerusalem, Jerusalem, Israel. ${ }^{9}$ University of Michigan, Ann Arbor, MI, USA. ${ }^{10}$ New York University, New York, NY, USA.

\section{Received: 9 June 2014 Accepted: 25 September 2014}

\section{Published online: 15 November 2014}

\section{References}

Ainsworth, SE, \& Loizou, A. (2003). The effects of self-explaining when learning with text or diagrams. Cognitive Science, 27, 669-681.

Ainsworth, SE, \& Saffer, J. (2013). Can children read trees? Merrill Palmer Quarterly, $59,221-247$

Allen, S. (2005). Finding Significance. San Francisco, CA: Left Coast Press. American Museum of Natural History. (2002). Assembling the Tree of Life: Harnessing Life's History to Benefit Science and Society (Brochure produced for the National Science Foundation based on three NSF Tree of Life workshops held in 1999 and 2000 at Yale University, the University of California Davis, and the University of Texas Austin). Retrieved August 30, 2010, from http://www.phylo.org/sub_sections/outreach/outreach_b.php.

Bapteste, E, O'Malley, MA, Beiko, RG, Ereshefsky, M, Gogarten, JP, Franklin-Hall, L, Lapointe, F, Dupre, J, Dagan, T, Boucher, Y, \& Martin, W. (2009). Prokaryotic evolution and the tree of life are two different things. Biology Direct, 4, 34.

Baum, DA, Smith, SD, \& Donovan, SS. (2005). The tree thinking challenge. Science, $310,979-980$

Block, F, Horn, M, Phillips, BC, Diamond, J, Evans, EM, \& Shen, C. (2012). The Deep Tree Exhibit: Visualizing the Great Tree of Life to Facilitate Informal Learning. Seattle WA: IEEE Information Visualization (InfoVis) Conference.

Catley, KM, \& Novick, LR. (2008). Seeing the wood for the trees: an analysis of evolutionary diagrams in biology textbooks. BioScience, 58, 976-987.

Catley, KM, \& Novick, LR. (2009). Digging deep: exploring college students' knowledge of macroevolutionary time. Journal of Research in Science Teaching, 46, 311-332.

Catley, KM, Novick, LR, \& Funk, DJ. (2012). The promise and challenges of introducing tree thinking into evolution education. In K Rosengren, EM Evans, S Brem, \& G Sinatra (Eds.), Evolution Challenges: Integrating Research and Practice in Teaching and Learning About Evolution (pp. 93-118). New York, NY: Oxford University Press.

Catley, KM, Phillips, BC, \& Novick, LR. (2013). Snakes and eels and dogs! Oh, my! Evaluating high school students' tree-thinking skills: an entry point to understanding evolution. Research in Science Education, 43, 2327-2348.

Chi, MTH, Bassok, M, Lewis, MW, Reimann, P, \& Glaser, R. (1989). Self-explanations: how students study and use examples in learning to solve problems. Cognitive Science, 13, 145-182.

Cracraft, J, \& Donoghue, MJ. (Eds) (2004). Assembling the Tree of Life. New York, NY: Oxford University Press.

Darwin, C. (1859). On the Origin of Species by Means of Natural Selection (1st ed.). London: John Murray.

Diamond, J, \& Evans, EM. (2007). Museums teach evolution. Evolution, 61, 1500-1506.
Diamond, J, \& Scotchmoor, J. (2006). Exhibiting evolution. Museums \& Social Issues, 1, 21-48.

Diamond, J, Zimmer, C, Evans, EM, Allison, L, \& Disbrow, S. (2005). Virus and the Whale: Exploring Evolution in Creatures Small and Large. Arlington, VA: National Science Teachers Association Press.

Dodick, J, \& Orion, N. (2003). Cognitive factors affecting student understanding of geologic time. Journal of Research in Science Teaching, 40, 415-442.

Doolittle, WF, \& Bapteste, E. (2007). Pattern pluralism and the tree of life hypothesis. Proceedings of the National Academies of Science, 104, 2043-2049.

Evans, EM. (2001). Cognitive and contextual factors in the emergence of diverse belief systems: creation versus evolution. Cognitive Psychology, 42, 217-266.

Evans, EM, Spiegel, A, Gram, B, Frazier, B, Tare, MS, Thompson, S, \& Diamond, J. (2010). A conceptual guide to natural history museum visitors' understanding of evolution. Journal of Research in Science Teaching, 47, 326-353.

Freeman, S. (2011). Biological science: Evolution, diversity, \& ecology (Vol. 2). Boston, MA: Benjamin Cummings.

Futuyma, DJ. (2004). The fruit of the tree of life. In J Cracraft \& MJ Donoghue (Eds.), Assembling the Tree of Life (pp. 25-39). New York, NY: Oxford University Press.

Futuyma, DJ. (2013). Evolution (3rd ed.). Sunderland, MA: Sinauer.

Giusti, E. (2008). Travels in the Great Tree of Life: A Summative Evaluation. Yale Peabody Museum. Accessed Oct 19, 2014 at http://www.exhibitfiles.org/dfile2/ ReviewFinding/242/original/ToL_Summative_Evaluation_Report.8.28.08.pdf.

Giusti, E, \& Scott, M. (2006). Tree of Life Visitor Study. Yale Peabody Museum. Accessed Oct 19, 2014 at http://www.exhibitfiles.org/dfile2/ReviewFinding/ 242/original/ToL__Front-end_evaluation.pdf.

Greene, TR. (1989). Children's understanding of class inclusion hierarchies: the relationship between external representation and task performance. Journal of Experimental Child Psychology, 48, 62-89.

Hampton, JA. (1988). Overextension of conjunctive concepts: evidence for a unitary model of concept typicality and class inclusion. Journal of Experimental Psychology: Learning, Memory, and Cognition, 14, 12-32.

Hegarty, M, \& Stull, AT. (2012). Visuospatial thinking. In KJ Holyoak \& RG Morrison (Eds.), Oxford handbook of Thinking and Reasoning. New York, NY: Oxford University Press.

Hegarty, M, Carpenter, PA, \& Just, MA. (1991). Diagrams in the comprehension of scientific texts. In R Barr, ML Kamil, P Mosenthal, \& PD Pearson (Eds.), Handbook of Reading Research (pp. 641-668). New York, NY: Longman.

Hurley, SM, \& Novick, LR. (2010). Solving problems using matrix, network, and hierarchy diagrams: the consequences of violating construction conventions. The Quarterly Journal of Experimental Psychology, 63, 275-290.

Kellman, PJ. (2000). An update on Gestalt psychology. In B Landau, J Sabini, J Jonides, \& E Newport (Eds.), Perception, Cognition, and Language: Essays in Honor of Henry and Lila Gleitman (pp. 157-190). Cambridge, MA: MIT Press.

Leinhardt, G, \& Crowley, K. (2002). Objects of learning. Objects of talk. Changing minds in museums. In SG Paris (Ed.), Perspectives on Object-Centered Learning in Museums (pp. 302-324). Mahwah, NJ: Lawrence Erlbaum Associates.

Lienau, EK, \& DeSalle, R. (2009). Evidence, content and corroboration and the tree of life. Acta Biotheoretica, 57, 187-199.

MacDonald, T, \& Wiley, EO. (2012). Communicating phylogeny: evolutionary tree diagrams in museums. Evolution Education and Outreach, 5, 14-28.

Matuk, CF. (2007). Images of evolution. Journal of Biological Communication, 33(3), E54-E61.

Matuk, CF, \& Uttal, DH. (2011). Narrative spaces in the representation and understanding of evolution. In KS Rosengren, SK Brem, EM Evans, \& GM Sinatra (Eds.), Evolution Challenges: Integrating Research and Practice in Teaching and Learning About Evolution. Oxford: Oxford University Press.

Meir, E, Perry, J, Herron, JC, \& Kingsolver, J. (2007). College students' misconceptions about evolutionary trees. The American Biology Teacher Online, 69(7), 71-76.

Mindell, DP. (2013). The tree of life: metaphor, model, and heuristic device. Systematic Biology, 62, 479-489.

Najjar, LJ. (1998). Principles of educational multimedia user interface design. Human Factors, 40, 311-323.

National Research Council. (2009a). A New Biology for the 21st Century (Committee on a New Biology for the 21st Century: Ensuring the United States Leads the Coming Biology Revolution. Board on Life Sciences. Division on Earth and Life Studies). Washington, DC: National Academies Press.

National Research Council. (2009b). Learning Science in Informal Environments: People, Places, and Pursuits. In P Bell, B Lewenstein, AW Shouse, \& MA Feder (Eds.), Committee on Learning Science in Informal Environments. Board on Science Education. Center for Education. Division of Behavioral and Social Sciences and Education. Washington, DC: The National Academies Press. 
Nelson, DL, Reed, VS, \& Walling, JR. (1976). Pictorial superiority effect. Journal of Experimental Psychology: Human Learning and Memory, 2, 523-528.

Novick, LR. (2001). Spatial diagrams: key instruments in the toolbox for thought. In DL Medin (Ed.), The Psychology of Learning and Motivation (Vol. 40, pp. 279-325). San Diego, CA: Academic.

Novick, LR, \& Catley, KM. (2007). Understanding phylogenies in biology: the influence of a Gestalt perceptual principle. Journal of Experimental Psychology: Applied, 13, 197-223.

Novick, LR, \& Catley, KM. (2013). Reasoning about evolution's grand patterns: college students' understanding of the tree of life. American Educational Research Journal, 50, 138-177.

Novick, LR, Catley, KM, \& Funk, JD. (2010). Characters are key: the effect of synapomorphies on cladogram comprehension. Evolution Education and Outreach, 3, 539-547.

Novick, LR, Catley, KM, \& Funk, JD. (2011a). Inference is bliss: using evolutionary relationship to guide categorical inferences. Cognitive Science, 35, 712-743.

Novick, LR, Shade, CK, \& Catley, KM. (201 1b). Linear versus branching depictions of evolutionary history: Implications for diagram design. Topics in Cognitive Science, 3, 536-559.

Paivio, A, \& Csapo, K. (1973). Picture superiority in free recall: imagery or dual coding? Cognitive Psychology, 5, 176-206.

Petre, M, \& Green, TRG. (1993). Learning to read graphics: some evidence that 'seeing' an information display is an acquired skill. Journal of Visual Languages and Computing, 4, 55-70,

Reinfeld, EL. (2010). Evaluating the Arthropod Tree of Life at the Harvard Museum of Natural History (Academic Report prepared for the School of Museum Studies): University of Leicester.

Sandvik, H. (2009). Anthropocentrism in cladograms. Biology and Philosophy, $24,425-440$

Scott, M. (2007). Rethinking Evolution in the Museum: Envisioning African origins. New York, NY: Routledge.

Scott, M. (2010). The pleasures and pitfalls of teaching human evolution in the museum. Evolution Education and Outreach, 3, 403-409.

Sweller, J, van Merrienboer, JJG, \& Paas, FGWC. (1998). Cognitive architecture and instructional design. Educational Psychology Review, 10, 251-296.

Tabbers, HK, \& de Koeijer, B. (2010). Learner control in animated multimedia instructions. Instructional Science, 38, 441-453.

Trend, RD. (1998). An investigation into understanding of geological time among 10- and 11-year old children. International Journal of Science Education, 20, 973-988.

Tversky, B, Zacks, J, Lee, PU, \& Heiser, J. (2000). Lines, blobs, crosses and arrows. In M Anderson, P Cheng, \& V Haarslev (Eds.), Theory and Application of Diagrams (pp. 221-230). Edinburgh: Springer.

Tversky, B, Morrison, JB, \& Betrancourt, M. (2002). Animation: can it facilitate? International Journal of Human-Computer Studies, 57, 247-262.

Weiss, M. (2006). Beyond the Evolution Battle: Addressing Public Misunderstanding. ASTC Dimensions. March/April, 3-5.

Wilson, EO. (2004). The meaning of biodiversity and the tree of life. In J Cracraft \& MJ Donoghue (Eds.), Assembling the Tree of Life (pp. 539-542). New York, NY: Oxford University Press.

Yates, TL, Salazar-Bravo, J, \& Dragoo, JW. (2004). The importance of the tree of life to society. In J Cracraft \& MJ Donoghue (Eds.), Assembling the Tree of Life (pp. 7-17). New York: Oxford University Press.

Yeh, Y-FY, \& McTigue, EM. (2009). The frequency, variation, and function of graphical representations within standardized state science tests. School Science and Mathematics, 109, 435-449.

doi:10.1186/s12052-014-0025-0

Cite this article as: Novick et al.: Depicting the tree of life in museums: guiding principles from psychological research. Evolution: Education and Outreach 2014 7:25.

\section{Submit your manuscript to a SpringerOpen ${ }^{\odot}$ journal and benefit from:}

- Convenient online submission

- Rigorous peer review

- Immediate publication on acceptance

- Open access: articles freely available online

- High visibility within the field

- Retaining the copyright to your article

Submit your next manuscript at $\gg$ springeropen.com 